\title{
Concepções de professores de ciências naturais de Caçapava do Sul (RS, Brasil) sobre geologia local: subsídios à educação geopatrimonial
}

\section{Conceptions of natural science school teachers from Caçapava do Sul (RS, Brazil) regarding local geology: clues for Geoheritage Education}

\author{
André Weissheimer de Borba ${ }^{1}$, Kathlem de Melo Teixeira ${ }^{2}$, Pedro Freitas Ferreira ${ }^{1}$, Patrícia de Freitas Ferreira ${ }^{2}$ \\ 1 - Universidade Federal de Santa Maria (UFSM), Depto. Geociências, Santa Maria/RS. - awborba.geo@gmail.com \\ 2 - Universidade Federal do Pampa (Unipampa), Caçapava do Sul/RS.
}

\section{Manuscrito: \\ Recebido: 24/06/2014 \\ Corrigido: 06/03/2015 \\ Aceito: 25/04/2015}

Citation: Borba A.W., Teixeira K. M., Ferreira P.F., Ferreira P.F.. 2015.Concepções de professores de ciências naturais de Caçapava do Sul (RS, Brasil) sobre geologia local: subsídios à educação geopatrimonial. Terræ Didatica, 11(2):117-124. <http://www.ige. unicamp.br/terraedidatica/> .

Keywords: Geoheritage education, survey, public schools, Caçapava do Sul.

\begin{abstract}
This paper reports the application of a survey for obtaining the profile and impressions of the natural science teachers of the public schools of Caçapava do Sul (Rio Grande do Sul, Brazil) about aspects of local geodiversity and its potential as an educational tool. The survey was filled in by 22 teachers (from a universe of around 50 professionals) who are mostly original from the local community, fact that is positive for community-based geo-educational strategies. Teachers self-evaluated their knowledge in geosciences (general and specific for Caçapava do Sul) as regular to restricted. On the other hand, they are optimistic with respect to the use of local geosites as teaching tools, and they are willing to increase their knowledge in geological sciences. The reported survey has also identified errors and misconceptions about the local nature and geology, which will be important in the development of geo-educational initiatives.
\end{abstract}

\section{Introdução, base teórica e objetivos da pesquisa}

O termo "geoconservação" (Sharples 2002, Brilha 2005, Henriques et al. 2011) designa o conjunto de iniciativas e estratégias destinadas a promover o conhecimento, a proteção, valorização, divulgação e uso sustentável dos geossítios, definidos como aquelas ocorrências que melhor representam a geodiversidade e a evolução geológica de uma região, ou seja, seu geopatrimônio (revisão de conceitos em Borba 2011). A geoconservação sustenta-se sobre quatro eixos principais: (1) o conhecimento, inventariação e avaliação dos geossítios; (2) a proteção legal das ocorrências geológicas, feições e paisagens de significativo valor, por exemplo, por meio de unidades de conservação da natureza (UC); (3) o desenvolvimento sustentável por meio da promoção do geoturismo/turismo geológico; e (4) a educação geopatrimonial, desenvolvendo nas comunidades escolares a consciência sobre a memória do planeta Terra e sobre a importância de sua preservação. O foco na educação é essencial uma vez que, segundo Gray (2008), a ignorância é a principal ameaça à integridade do geopatrimônio.

O município de Caçapava do Sul $\left(3.047 \mathrm{~km}^{2}\right.$, 33 mil habitantes), na chamada "metade sul" do Rio Grande do Sul, pode ser considerado a "capital gaúcha da geodiversidade” (Borba et al. 2013b). Ali afloram os principais grupos de rochas (ígneas vulcânicas e plutônicas, metamórficas, sedimentares), em exposições pontuais e feições do relevo acessíveis e dotadas do mais alto valor didático e científico. Um inventário recente (Borba et al. 2013a) identificou 46 geossítios, reunidos em quatro contextos geológicos (Fig. 1). O primeiro contexto contempla um conjunto de unidades antigas, sobretudo metamórficas, de embasamento (2,5 a 0,7 bilhões de anos), incluindo alguns dos zircões detríticos mais antigos do Brasil e rochas da crosta oceânica (ofiolitos). Fazem parte ainda desse contexto mármores calcíticos e dolomíticos, sugestivos de um "paraíso tropical" do passado geológico, pois derivam do metamorfismo de cal- 


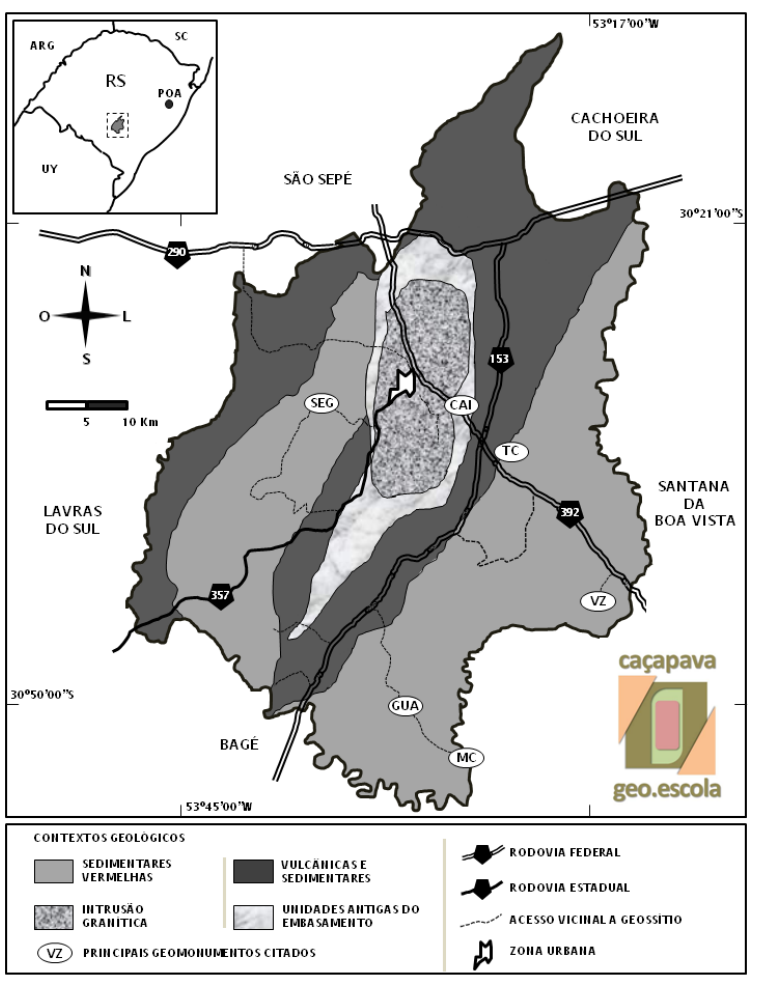

Fig. 1 Mapa esquemático do município de Caçapava do Sul ("metade sul" gaúcha) ilustrando os quatro principais contextos geológicos registrados no território (modif. de Borba et al. 2013a); no detalhe do canto superior esquerdo, a localização do município de Caçapava do Sul (em cinza escuro) dentro do Rio Grande do Sul e em relação à capital Porto Alegre (POA), e aos países/estados vizinhos, Uruguai (UY), Argentina (ARG) e Santa Catarina (SC); no detalhe do canto inferior direito, o logotipo do projeto "caçapava geo.escola", em execução na Universidade Federal de Santa Maria; os geomonumentos citados no texto e apontados nesta figura são a Serra do Segredo (SEG), as Guaritas (GUA), as Caieiras (CAI), as Minas do Camaquã (MC), a Toca das Carretas (TC) e a Gruta da Varzinha (VZ).

cários depositados em um mar raso e quente. $\mathrm{O}$ segundo contexto compreende rochas vulcânicas de diferentes composições e afinidades, formadas por erupções de diversos estilos, acompanhadas de rochas sedimentares derivadas de deposição marinha e lacustre (630 a 550 milhões de anos). O terceiro contexto está circunscrito a uma intrusão ígnea ( $>550$ milhões de anos) de composição diversificada, incluindo desde dioritos até granitos muito evoluídos, ricos em sílica, os quais, por sua significativa resistência ao intemperismo químico, formam o alto topográfico onde se localiza a zona urbana de Caçapava do Sul. Por fim, o quarto contexto engloba rochas sedimentares continentais do Paleozóico inferior ( $\sim 500$ milhões de anos), de coloração avermelhada, de origem fluvial, lacustre e eólica, expostas em regiões de relevo ruiniforme e beleza cênica destacada, como a Serra do Segredo (Fig. 2A) e as Pedras das Guaritas (Fig. 2B, Borba et al. 2011, Paim et al. 2010).

Ao levar-se em conta a geodiversidade descrita acima, percebe-se que Caçapava do Sul constitui uma incomparável sala de aula ao ar livre para o ensino de geociências, além de contar com uma série de atrativos potenciais nos campos do geoturismo, ecoturismo e esportes de aventura na natureza. Toda essa diversidade e esse potencial, no entanto, não se refletem nos números do desenvolvimento econômico e humano do município. Isso é particularmente verdadeiro ao se observarem os números de exames nacionais como o Índice de Desenvolvimento da Educação Básica (IDEB) e o Exame Nacional do Ensino Médio (ENEM), especialmente aqueles relacionados às ciências da natureza (INEP 2014a,b). Por exemplo, os números do IDEB para a rede pública de educação básica de Caçapava do Sul (INEP, 2014a) apontam que as metas projetadas não foram alcançadas e que, mais do que isso, para o $9^{\circ}$ ano, o desempenho em 2011 caiu em comparação com 2009. No ENEM, do qual alunos de apenas duas escolas públicas da cidade participaram em 2011, 64,8\% dos concluintes de uma escola e $77,1 \%$ da outra obtiveram notas abaixo de 500 (dos 1000 pontos possíveis) em ciências da natureza (INEP, 2014b). Ainda, a partir de observações qualitativas, é notável o fato de que muitos estudantes caçapavanos deixam a cidade (para estudar em Santa Maria ou Porto Alegre) sem chegarem a conhecer a maioria (e muitas vezes, sem conhecer nenhum) dos geossítios de seu município.

Iniciativas de educação geopatrimonial, dentro de um programa mais abrangente de geoconservação, parecem ser as ferramentas ideais para o enfrentamento desses problemas. Na Europa, especialmente em Portugal (onde a geologia é uma das disciplinas do Ensino Médio), e principalmente nos territórios designados como geoparques (McKeever e Zouros 2005), a utilização dos geossítios e de outros materiais geológicos na escola é muito difundida. Constante (2010), por exemplo, chama a atenção para atividades lúdico-práticas, como jogos sobre o "ciclo das rochas" e maquetes de papel para os diferentes limites entre placas tectônicas, citando também o grande potencial de quebra-cabeças e jogos computacionais sobre a "motivação dos alunos". A complexidade do tempo geológico e sua percepção por parte de alunos portugueses foi o 


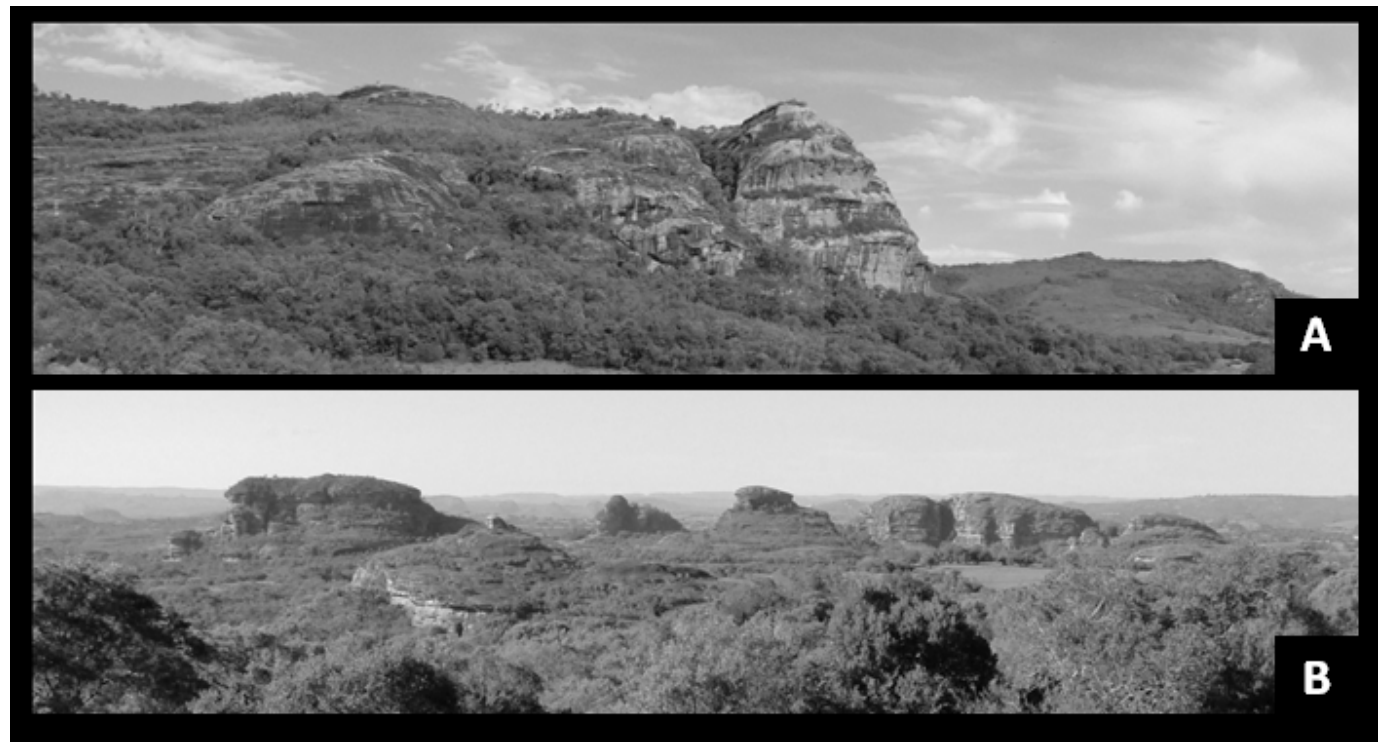

Fig. 2 Os dois principais geomonumentos do município de Caçapava do Sul, com especial potencial para a educação geopatrimonial: (a) Serra do Segredo e (b) Pedras das Guaritas; as localizações estão indicadas na Fig. 1.

tema do trabalho de Bonito et al. (2011), que reconheceu dificuldades na compreensão do conceito e da correta ligação entre os fenômenos geológicos e sua duração. Henriques et al. (2012) realizou um trabalho abrangente sobre o papel do Geoparque Arouca como recurso educacional, porém ainda identificou vários equívocos, mitos e dificuldades de compreensão sobre o conteúdo geológico e sua dimensão patrimonial.

No Brasil, podem ser citados, como exemplos de iniciativas (todas em fase preliminar ou de coleta de dados) de educação geopatrimonial: (1) o levantamento realizado por Santos e Carvalho (2012) sobre a percepção e os conhecimentos dos professores com atuação na região do Parque Paleontológico de São José de Itaboraí, onde ficou constatado o precário conhecimento dos educadores sobre a geologia e a arqueologia locais, e que servirá de base para iniciativas de educação específica na área; e (2) as oficinas sobre geologia realizadas em Antonina, durante a programação do "Festival de Inverno" daquela cidade litorânea paranaense (Mesquita et al. 2011), onde a principal conclusão foi de que não basta o envolvimento de graduandos em geologia nessas atividades, sendo necessária a capacitação dos professores que já atuam na educação básica em temas relacionados às geociências; e (3) o programa "Rocha Amiga" (Ruchkys et al. 2012), idealizado em Portugal (Cachão et al. 2008) e adotado pelo território (aspirante à certificação como geoparque) do "Quadrilátero Ferrífero" (MG), e que integra roteiros de visita a geomonumentos selecionados e construção de "kits pedagógicos" com amostras de rocha da referida região.

Dentre os objetivos do projeto "caçapava geo. escola", sob responsabilidade do primeiro autor, encontra-se a difusão mais eficiente da informação geocientífica, em linguagem acessível, aos professores da educação básica da rede pública de Caçapava do Sul e a seus estudantes, por meio de oficinas, palestras e do estímulo ao uso do geopatrimônio local em suas aulas de ciências. Antes de qualquer ação, no entanto, é necessário conhecer o público-alvo, seu nível de conhecimento sobre o assunto e seus anseios com relação ao tema. Isso foi realizado por intermédio de um levantamento (survey) do perfil e das impressões dos professores de ciências, ciências da natureza, geografia e biologia (ensinos fundamental e médio) sobre as características geológicas do município. Esses profissionais são os responsáveis, em diferentes momentos da educação básica, por repassar aos alunos noções de geologia e geomorfologia. Os resultados do perfil são expostos neste artigo, para servir como base para futuras iniciativas e estratégias de geoconservação e educação geopatrimonial.

\section{Metodologia: 0 instrumento de pesquisa}

O levantamento do perfil e das impressões dos professores da rede pública de Caçapava do Sul foi realizado com a anuência e a colaboração da Secretaria Municipal de Educação de Caçapava do Sul (SMEDUC) e, no caso das escolas estaduais, das diretoras e vice-diretoras daqueles estabelecimentos de ensino. O número total de professores que atuam 
no ensino de ciências, geografia e biologia na rede pública (municipal e estadual) de Caçapava do Sul, à época de distribuição dos questionários (ano de 2013), aproximava-se de 50 licenciados. O número exato de professores e o número daqueles que realmente estão em atividade docente são difíceis de obter, uma vez que muitos professores estão tanto na rede municipal quanto na estadual, e as informações por vezes são discrepantes. A intermediação da SMEDUC e das direções das escolas estaduais permitiu a distribuição de tais questionários a praticamente todos os profissionais, dos quais 22 responderam a consulta. A taxa de retorno dos questionários fica, assim, um pouco abaixo de $50 \%$, o que permite um desenho relativamente fiel do perfil dos professores em atividade no município.

O questionário distribuído foi montado com base em diretrizes apontadas por Mattar (1994) e Günther (2003). Tinha identidade visual própria, com destaque para o logotipo do projeto, uma versão estilizada e geométrica do mapa de grandes contextos geológicos do município (detalhe no canto inferior direito do mapa da Fig. 1). Em primeiro lugar, contava com um texto inicial de meia página destinado a explicar aos entrevistados a proposta do projeto "caçapava geo.escola" e a convidá-los a contribuir com suas respostas na construção das ações futuras. Logo após, havia espaço para a identificação pessoal (opcional), idade, sexo, local de nascimento, o(s) curso(s) de graduação cursado(s) e a(s) escola(s) onde se graduou, além da data de admissão na rede pública de Caçapava do Sul como professor. Seguia-se a esse perfil uma autoavaliação, com duas questões fechadas, seguindo o padrão da abordagem mais geral para a mais específica (Günther 2003): (1) "como você classificaria, atualmente, seu nivel de conhecimento sobre aspectos gerais de geologia e geomorfologia?"; e (2) "como você classificaria seu nivel de conhecimento sobre a geologia e a geomorfologia (ou seja, a geodiversidade) de Caçapava do Sul?". As alternativas para marcação, seguindo o princípio do equilíbrio entre alternativas consideradas boas e ruins, eram "excelente", "muito bom", "bom", "regular", "restrito" e "insuficiente". A essas questões fechadas, seguia-se uma solicitação ao entrevistado para que listasse as principais razões para sua autoavaliação.

Uma breve explicação era fornecida, então, sobre o significado dos termos "lugares de interesse geológico", "geossítios", "geomonumentos" ou "geolugares" que, para efeitos desta pesquisa, constituem sinônimos. É útil salientar que, no âmbito deste trabalho, o uso do vocábulo "lugar" refere-se a seu significado na linguagem coloquial, do dia-a-dia, e não como um conceito geográfico elaborado. $\mathrm{O}$ instrumento, então, convidava os professores a listarem geomonumentos que lhes viessem à mente no Brasil e no Rio Grande do Sul (questão 3), na região de Caçapava do Sul (questão 4) e, por fim, a informarem os geomonumentos caçapavanos que efetivamente conheciam in loco, tentando esboçar o que tais locais representavam em termos de história natural e evolução geológica (questão 5). A questão 6 perguntava se o professor utiliza, ou se já utilizara, em visitas a campo ou em sala de aula (mesmo que por meio de fotografias), geossítios do município de Caçapava do Sul como exemplos de feições ou processos geológicos, quais sítios, com que frequência e o porquê dessa utilização ou não utilização.

A questão 7, "como você classificaria o potencial didático/educacional da geodiversidade (aspectos de geologia e geomorfologia) de Caçapava do Sul na área das ciências da natureza?", tinha as alternativas "excelente", "bom", "regular", "restrito", "nenhum/nulo" e "não sei responder". A questão 8, "você considera que a utilização de geomonumentos locais como ferramentas didáticas/educacionais pode aumentar o interesse e/ou melhorar o desempenho de seus alunos de ciências da natureza?", permitia as opções "sim, com certeza", "talvez, é possivel", "não faria diferença" e "não sei responder". Nas questões 7 e 8, conforme exposto acima, optou-se por um número ímpar de alternativas concretas, balanceadas (Günther 2003), e uma opção adicional no sentido de manifestar a incapacidade de responder. Por fim, a questão 9 pretendia averiguar sobre a disposição do professor em participar de cursos gratuitos na área, com professores de geociências, e incluía um espaço para que o professor listasse tópicos sobre os quais quisesse receber mais informações, especificamente com relação à temática abordada no questionário. O entrevistado ainda contava com um espaço para outras manifestações que desejasse expor sobre o objeto do levantamento. Seguindo as orientações de Günther (2003), o questionário era finalizado com um agradecimento pela participação e com uma mensagem de "excelente ano letivo!".

\section{Resultados e discussão}

\section{Perfil dos professores}

Os professores responsáveis pelo ensino de ciências da natureza, geografia e biologia da rede pública de Caçapava do Sul que retornaram o ques- 
tionário são gaúchos (100\%), nascidos em sua grande maioria na região centro-sul do Estado do Rio Grande do Sul (91\%), sendo que a maior frequência é de professores caçapavanos (63\%). Considerando-se os princípios e objetivos da geoconservação e da educação geopatrimonial, essa maioria de professores locais é adequada e importante para o comprometimento, a possibilidade de permanência no local e a identificação com o município e seu patrimônio. Dos que responderam, $86 \%$ são mulheres, sua média de idade é de 43 anos (com idades de 25 a 62 anos), e sua média de tempo de atuação como professores da rede pública de Caçapava do Sul é de 14,3 anos.

Os 22 professores citaram 24 faculdades/cursos como as escolas em que obtiveram seus diplomas, discrepância devida ao fato de que alguns frequentaram e se graduaram em mais de um curso (diferentes modalidades de licenciatura ou bacharelado): $68 \%$ deles (15 dos 22) foram graduados pela Universidade da Região da Campanha (URCAMP), em diferentes cursos/campi. Dos 22 professores, 9 são licenciados em Biologia ou Ciências Biológicas (sendo 8 pela URCAMP), 6 são licenciados em Ciências Sociais (todos pela URCAMP), e 4 são licenciados em Estudos Sociais (todos esses quatro com idade acima de 49 anos). Os demais cursos citados foram Ciências, Geografia, História, Matemática e Pedagogia (um professor de cada graduação). Os dados aqui expostos apontam a importância de se incluir a URCAMP, mesmo diante da recente notícia do fechamento de seu campus de Caçapava do Sul, em iniciativas e estratégias de geoconservação, além da necessidade de se integrar os estudantes daquela universidade com os estudantes/docentes da Universidade Federal do Pampa (Unipampa), cujo campus caçapavano é dedicado às ciências da Terra (especialmente aos cursos de geologia e geofísica).

\section{Autoavaliação e impressões dos professores}

Perguntados sobre como avaliavam seu nível de conhecimento em aspectos gerais de geologia e geomorfologia (Fig. 3A), os professores responderam: "regular" (36,4\%) e "restrito" (31,8\%), "bom" (22,7\%) e "insuficiente" (9,1\%). Especificamente com relação ao seu conhecimento das características de geologia e geomorfologia de Caçapava do Sul, as respostas de maior frequência também foram "regular" (40,9\%) e "restrito" (36,4\%), enquanto "bom" (13,6\%) e "insuficiente" (9,1\%) também foram alternativas escolhidas (Fig. 3B). Para exemplificar algumas das razões elencadas para essa insatisfação com seus conhecimentos em geociências, transcrevem-se algumas manifestações de professores da área de Ciências Biológicas: "não tive conhecimento nessa área", "o assunto é tratado sucintamente no curso", "vi muito pouco na faculdade" e "não tive nenhuma disciplina voltada à geologia". Outros citaram "falta de cursos/ eventos na área" e "falta de material didático específico". Os mais satisfeitos com seu conhecimento citaram a realização de cursos de pós-graduação e de formação continuada (inclusive no Departamento de Geologia da Unisinos, em São Leopoldo).

Entre os geossítios brasileiros e sul-rio-grandenses mais citados, estão os "Aparados da Serral Itaimbezinho", em Cambará do Sul (10 citações), as "Guaritas" (10), as "Minas do Camaquã" (9), a "Pedra do Segredo" (9), esses três no próprio município de Caçapava do Sul, e ainda a "Chapada dos Guimarães”, no Mato Grosso (4), entre muitos outros geossítios referidos. Especificamente com relação a lugares de interesse geológico de Caçapava do Sul, todos os principais geossítios da região (Guaritas, Pedra do Segredo, Gruta da Varzinha, Toca das Carretas, Caieiras, Minas do Camaquã, entre outros) foram mencionados pelos professores. No entanto, poucos os utilizam como ferramentas de ensino ou, se já utilizaram, deixaram de fazê-lo por falta de recursos financeiros ou apoio logístico das escolas.

Perguntados sobre como avaliavam o potencial didático/educacional dos geomonumentos de Caçapava do Sul (Fig. 3C), os professores responderam que esse potencial era "excelente" (36,4\%), "regular" (22,7\%), "bom" (13,6\%) e "restrito" (13,6\%). Outros professores não souberam responder $(13,6 \%)$, tendo um deles se manifestado da seguinte maneira: "deve ser bom, mas os professores não recebem formação adequada para utilizá-lo". No entanto, os professores se mostraram otimistas, pois $86,4 \%$ responderam estar convencidos de que a utilização dos exemplos locais poderá melhorar o desempenho de seus estudantes em ciências da natureza. Além disso, estão dispostos a incrementar seu conhecimento na área da geologia $\mathrm{e}$ geomorfologia $(95,4 \%)$, o que confirma a pertinência e a oportunidade do projeto "caçapava geo.escola" e da própria inserção de uma ideia de geoconservação e educação geopatrimonial no município.

\section{Equívocos e mitos como subsídios à educação geopatrimonial}

Um aspecto interessante do questionário aplicado diz respeito à questão que solicitava que os 


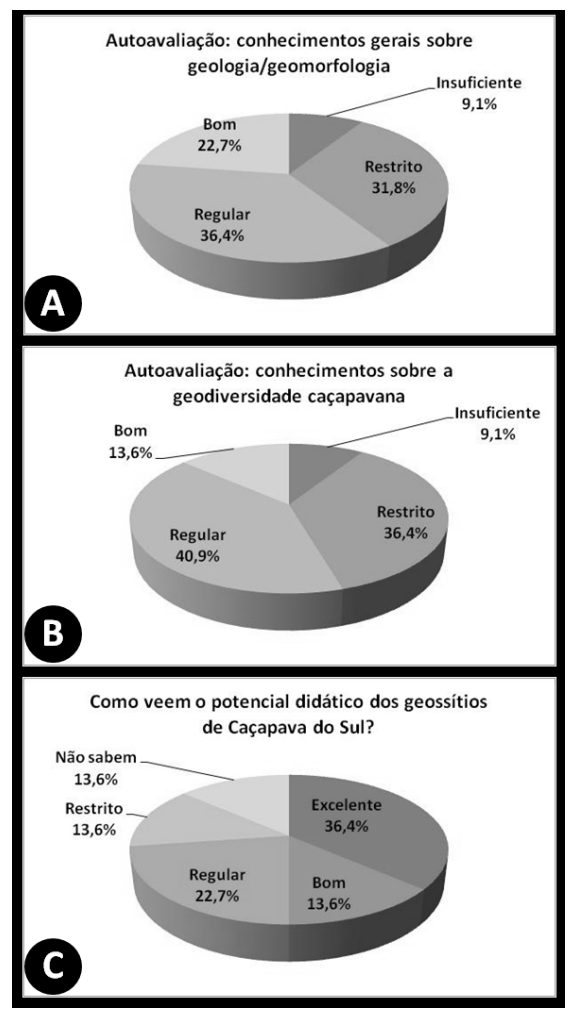

Fig. 3. Gráficos ilustrando as respostas fornecidas pelos professores de Caçapava do Sul a três das perguntas do questionário: $(A)$ como avaliavam seu conhecimento geral sobre geologia e geomorfologia; (B) como avaliavam seu conhecimento sobre a geodiversidade de Caçapava do Sul; e (C) de que forma viam o potencial didático dos geossítios caçapavanos.

professores tentassem esboçar o que cada geomonumento (citado por eles, na questão dos geossítios que eles afirmam conhecer) representava em termos de história natural e evolução geológica. Algumas das "explicações geológicas" fornecidas pelos professores consistem, na verdade, em equívocos, mitos, ou informações imprecisas. Muitos desses equívocos resultam não apenas da falta de interesse em buscar a informação correta, ou de deficiências na formação em graduação, mas da própria dificuldade que os geólogos e professores de geologia possuem para transmitir seu conhecimento de forma mais acessível a um público não-especializado (e.g. Brilha 2004).

Alguns desses equívocos relacionam-se com o próprio conjunto de conhecimentos das diferentes profissões. Por exemplo, mesmo que os termos "geologia", "geomorfologia", "geossítios" e/ou "geomonumentos" tenham sido exaustivamente utilizados na construção do questionário, algumas respostas fazem referência a outras áreas do conhecimento: "(...) a maioria dos sítios arqueológicos de Caçapava é de formação arenítica", ou "os lugares possuem vários potenciais arqueológicos", em clara confusão entre os objetos de estudo da geologia e da arqueologia. Longe de ser apenas uma observação, a ocorrência de tais respostas representa subsídio importante para oficinas, palestras e minicursos, os quais devem iniciar por esclarecimentos com relação ao papel da geologia e sua diferenciação com relação às demais ciências, sejam naturais ou humanas/sociais.

Outros mitos identificados relacionam-se aos ambientes de formação das rochas no mais destacado geomonumento de Caçapava do Sul: as "Guaritas" ou "Pedras das Guaritas". O geossítio (Fig. 2b), inscrito na lista SIGEP do patrimônio geológico brasileiro (Paim et al. 2010), é composto por arenitos e conglomerados avermelhados, formados por sistemas fluviais entrelaçados e dunas eólicas de um deserto do Paleozóico inferior $(\sim 500$ milhões de anos), expostos em um relevo ruiniforme esculpido pelo vento e pela chuva, em fases de alternância entre climas mais secos e mais úmidos. No entanto, algumas manifestações dos professores entrevistados dão conta de que as Guaritas seriam "formações rochosas com predomínio do granito". De fato, há granitos em Caçapava do Sul, mas não na região das Guaritas. Outras respostas explicavam aquela região como possuindo "formações vulcânicas (...) trabalhadas pela água que as cobria". Há rochas vulcânicas em abundância no município mas, novamente, não nas Guaritas. Ainda com relação àquele geomonumento, alguns respondentes informaram que essas formações mostravam como seria o ambiente no passado, "coberto de água do mar, e com várias formas de vida", e ainda "com fósseis de várias eras geológicas". Vale lembrar que as rochas que formam o substrato das Guaritas são rochas continentais, formadas em ambiente desértico, sem qualquer influência marinha, de um período da evolução da Terra (Paleozóico inferior) em que ainda não havia qualquer forma de vida sobre os continentes e que, portanto, a unidade estratigráfica Guaritas é desprovida de fósseis (afossilífera).

\section{Considerações finais}

O levantamento efetuado por meio de questionário aos professores da rede pública de educação básica de Caçapava do Sul, com intermediação da SMEDUC local e das direções dos colégios estaduais, resultou em uma série de informações e sub- 
sídios valiosos na formatação de futuras iniciativas de geoconservação e educação ambiental/geopatrimonial que envolvam as escolas do município:

A - Os professores, em sua maioria, têm origem no próprio município ou em cidades vizinhas, o que é positivo para a aplicação de iniciativas que tratem das características locais; esses professores muito provavelmente irão permanecer no município e possuem uma motivação adicional na tarefa de gerar orgulho em seus alunos pela geodiversidade local;

B - Os professores pesquisados possuem conhecimento de regular a restrito com relação a geociências e às características geológicas de Caçapava do Sul, o que confirma a pertinência de projetos de educação geopatrimonial; estão dispostos a receber informações e qualificação por meio da interação com profissionais das geociências em oficinas, palestras ou minicursos, e consideram que isso poderá ajudar na solução de alguns problemas relacionados ao ensino de ciências;

C - O perfil levantado evidencia que qualquer estratégia mais ampla de geoconservação no município (ou na região como um todo) deverá envolver obrigatoriamente a URCAMP, mesmo com o fechamento do campus de Caçapava do Sul, pois seus egressos compõem a maior parte dos professores responsáveis por prover uma base sólida em ciências (inclusive em ciências da Terra) aos estudantes locais;

D - Palestras, oficinas e/ou minicursos deverão incluir um tópico de esclarecimento com relação ao papel das geociências, além de sua interação e diferenciação com relação a outras ciências naturais (biologia, química, etc.) ou humanas/sociais (história, arqueologia, etc.);

E - As atividades, além de um conteúdo geral e direcionado à geodiversidade local, deverão incluir esclarecimentos com relação a mitos e informações imprecisas ou incorretas sobre os diferentes geomonumentos de Caçapava do Sul.

Cabe ainda uma discussão sobre a formação inicial dos professores, que claramente não é a mais adequada ao ensino de geociências na educação básica. No universo pesquisado, de 22 professores, não há geólogos, e apenas um é graduado em geografia, licenciatura que mais se aproxima dos tópicos de geologia, mas que ainda assim enfatiza os aspectos humanos e socioeconômicos nos cursos oferecidos pelas escolas gaúchas. Além disso, conforme demonstrado acima, os licenciados nas biociências manifestam falta de preparo em tópicos relacionados à natureza abiótica. A situação ideal envolveria a participação de professores com formação inicial consistente em geologia na oferta dessas disciplinas à educação básica. Sabe-se, no entanto, que a realidade do interior do Brasil, em geral, e da "metade sul" gaúcha, em particular, é de profunda carência de professores na educação básica. Portanto, iniciativas de qualificação e aperfeiçoamento dos professores que já atuam no município constituem, em curto prazo, a melhor alternativa para o melhor aproveitamento dessa verdadeira sala de aula ao ar livre que é o município de Caçapava do Sul.

\section{Agradecimentos}

Os autores agradecem o apoio institucional da Secretaria Municipal de Educação de Caçapava do Sul (SMEDUC/CS), nas pessoas da titular da pasta, Professora Maureli Lopes de Melo, e da coordenadora da área de ciências, Professora Tamiris Sinnemann. Reconhecem, ainda, a colaboração das diretorias das escolas públicas estaduais e municipais de Caçapava do Sul na distribuição e recolhimento do instrumento de pesquisa. Agradecem, por fim, os 22 professores que gentilmente responderam o questionário enviado e que, dessa forma, viabilizaram a elaboração deste trabalho.

\section{Referências}

Bonito J., Rebelo D., Morgado M., Monteiro G., Medina J., Marques L., Martins L. 2011. A complexidade do tempo geológico e a sua aprendizagem com alunos portugueses (12-13 anos). Terrae Didatica, 7(2):81-92.

Borba A.W. 2011. Geodiversidade e geopatrimônio como bases para estratégias de geoconservação: conceitos, abordagens, métodos de avaliação e aplicabilidade no contexto do Estado do Rio Grande do Sul. Pesq. Geoc., 38(1):3-13.

Borba A.W., Souza L.F., Porto P.R., Petry A.C. 2011. A paisagem da Serra do Segredo (Caçapava do Sul, RS) como patrimônio geológico brasileiro: características, riscos à integridade e estratégias de conservação. In: Simp. Bras. Patrim. Geol., 1, 
Rio de Janeiro, 2011. Atas..., Rio de Janeiro, SBG (Núcleo RJ-ES), p. 9.

Borba A.W., Souza L.F., Mizusaki A.M.P., Almeida D.P.M., Stumpf P.P. 2013a. Inventário e avaliação quantitativa de geossítios: exemplo de aplicação ao patrimônio geológico do Município de Caçapava do Sul (RS, Brasil). Pesq. Geoc., 40(3):275-294.

Borba A.W., Lusa M., Figueiró A.S., Da Rosa A.A.S., Ferreira P.F., Souza L.F. 2013b. Geoconservação em Caçapava do Sul (RS, Brasil): potencial versus realidade na "capital gaúcha da geodiversidade". In: II Simp. Bras. Patr. Geol., Ouro Preto, Anais (PDF), p. 29-30.

Brilha J.B.R. 2004. A geologia, os geólogos e o manto da invisibilidade. Comunicação e Sociedade (Portugal), 6:257-265.

Brilha J.B.R. 2005. Património geológico e geoconservação. Braga: Palimage Eds, Viseu, 190p.

Cachão M., Brilha J.B.R., Matias L., Sá A., Lopes P. 2008. Rocha Amiga. Projecto Pedagógico integrado ao Ano Internacional do Planeta Terra. Memórias e Notícias (Portugal), 3:293-300.

Constante A. 2010. Actividades lúdico-práticas no ensino da Geologia: complemento motivacional para a aprendizagem. Terrae Didatica, 6(2):101-123.

Gray M. 2008. Geodiversity: developing the paradigm. Proc. Geol. Assoc., 119:287-298.

Günther H. 2003. Como elaborar um questionário. In: Série Planejamento de Pesquisa nas Ciências Sociais, n.01, Brasília, DF, UnB, Laboratório de Psicologia Ambiental. URL: http://www.psi-ambiental. net/pdf/01Questionario.pdf. Acesso 14.09.2013.

Henriques M.H., Pena dos Reis R., Brilha J.B.R., Mota T. 2011. Geoconservation as an emerging geoscience. Geoheritage, 3:117-128.

Henriques M.H., Tomaz C., Sá A.A. 2012. The Arouca Geopark (Portugal) as an educational resource: a case study. Episodes, 35(4):481-488.

INEP. Instituto de Estudos e Pesquisas Educacionais Anísio Teixeira. 2014a. IDEB Índice de Desenvolvimento da Educação Básica. Resultados para o município de Caçapava do Sul. URL: http:// ideb.inep.gov.br/resultado/resultado/resultado. seam?cid=9140214. Acesso 13.03.2015.

INEP. Instituto de Estudos e Pesquisas Educacionais Anísio Teixeira. 2014b. ENEM 2011 por Escola. URL: http://portal.inep.gov.br/web/enem/enempor-escola. Acesso 13.03.2015.

Mattar F.N. 1994. Pesquisa de marketing: metodologia, planejamento, execução e análise. $2^{\mathrm{a}}$ ed. São Paulo: SP, Atlas. v. 2.

McKeever P., Zouros N. 2005. Geoparks: celebrating Earth heritage, sustaining local communities. Episodes, 28(4):274-278.

Mesquita M.J.M., Picanço J.L., Besser M.L., Ribeiro J.C., Dmeterko H., Silva A.L., Cruz G.M., Acordes F.A., Ribeiro P.R., Hamerschmidt T., Morais, J.E.F., Berton F., Mattos R.F., Schemiko D.C.B. 2011. A experiência da oficina "Do mito à natureza: educar o olhar para as Ciências da Terra" no Festival de Inverno de Antonina (PR). Terrae Didatica, 7(2):75-85.

Paim P.S.G., Fallgater C., Silveira A.S. 2010. Guaritas do Camaquã, RS: exuberante cenário com formações geológicas de grande interesse didático e turístico. In: Winge, M., Schobbenhaus, C., Souza, C.B.G., Fernandes, A.C.S., Berbert-Born, M., Sallun-Filho, W. \& Queiroz, E.T. eds. 2010. Sítios geológicos e paleontológicos do Brasil (publicado na internet em 30/8/2010 no sítio www.unb.br/ ig/sigep/sitio076/sitio076.pdf).

Ruchkys U., Machado M.M.M., Cachão M. 2012. Programa Rocha Amiga, Iniciativas para crianças do Ensino Fundamental no Quadrilátero Ferrífero, Minas Gerais, Brasil. Anuário Inst. Geoc. UFRJ, 35(1):261-270.

Santos W.F.S., Carvalho I.S. 2013. Percepção dos professores do entorno do Parque Paleontológico de São José de Itaboraí (RJ) sobre aspectos geológicos, paleontológicos e arqueológicos locais. Terrae Didatica, 9:50-62.

Sharples C. 2002. Concepts and principles of geoconservation. Tasmanian Parks and Wildlife Serv. 81p. (electronic publ.).

Resumo: 0 trabalho relata a aplicação de um levantamento (survey) realizado com os professores da área de ciências da rede pública de educação básica de Caçapava do Sul (RS, Brasil) sobre a geodiversidade local e seu potencial no ensino. 0 questionário foi respondido por 22 professores (de um universo próximo a 50 profissionais). 0s respondentes são, em sua maioria, cidadãos oriundos da própria comunidade caçapavana, o que é positivo em termos de identificação com o município e com seus alunos. Os professores consideram seu conhecimento em geologia (geral e específico sobre Caçapava do Sul) regular a restrito, mostram-se otimistas com relação ao uso dos geossítios locais como ferramentas de ensino e dispostos a incrementar seu conhecimento e suas aulas nos aspectos relacionados às ciências da Terra. 0 levantamento ainda identificou mitos, confusões e equívocos sobre a geologia local, os quais serão importantes subsídios para atividades de educação geopatrimonial.

PALAVRAS-CHAVE: educação geopatrimonial, levantamento (survey), escolas públicas, Caçapava do Sul. 